\title{
Íki Yönlü Tablolarda Uyum Analizi Tekniğinin Kullanımı
}

\author{
Ensar BAŞPINAR'
}

\author{
Mehmet MENDEŞ²
}

\author{
Geliş Tarihi : 14.02 .2000
}

\begin{abstract}
Özet: Bu çaiıșmada, iki yönlù tablolanın analizinde yaygin olarak kullantlan $\chi^{2}$-testi, G-istatistiği ve oranlara ait $Z$. Testine bir alternatif olarak Uyum Analizi (Correspondence Analysis) tekniği ele alınmıştır. Bu tekniğin uygulama aşamaları adım adım açıklanmış, diğer yöntemlere göre avantaj ve dezavantajları belirtilmiştir. Analiz tekniğinin adimlarına ait bir örnek, iki yönlü tablo üzerinde gösterilmiştir. Uyum analizi tekniği ile elde edilebilecek bilgi kalite ve miktarımın diğer yöntemlerden daha yüksek olduğu sonucuna varıımıştır
\end{abstract}

Anahtar Kelimeler: Uyum analizi, kategorik veri, iki yönlü tablo, $\chi^{2}$-testi, G-istafistigi

\section{The Usage of Correspondence Analysis Technique at the Contingency Tables}

\begin{abstract}
Correspondence Analysis is handled as an alternative technique to $x^{2}$-test, GStatistics and Z-test for proportions in analysis of contingency tables. The application stages of Correspondence analysis are explained step by step and advantages and disadvantages are determined with respect of the other techniques. The application stages were given in an example contingency table. As a result, the usage of this technique was more suitable than the other techniques given.
\end{abstract}

Key words: Correspondence analysis, categorical data, contingency table, $\chi^{2}$-test, $G$-statistics

\section{Giriş}

Uzerinde durulan özellik ya da özellikler bakımından, veriler farklı tiplerde elde edilebilir. Bazı araștirmalarda ölçmek, tartmak veya analiz etmek suretiyle elde edilirken bazı araștırmalarda saymak suretiyle ,var-yok şeklinde (binary), bazen de ya doğrudan kategorik bir șekilde elde edilir ya da elde edildikten sonra kategorize edilebilitler. Verilerin elde ediliş şekillerinin bilinmesi, buniarin değerlendirilmesi aşamasında kullanılacak istatistik tekniği ile doğrudan ilișkili olduğundan çok önemlidir. (Sokal ve Rohif 1995)

Kategorik olarak elde edilmiş ya da elde edildikten sonra kategorize edilmiş verilerin analizi lile daha ziyade sosyal bilimlerde çok sık karşılaşılmaktadir. Bu tip verilere fen bilimlerinde başła tup olmak üzere biyolojide, veteriner ve tarım bilimlerinde de oldukça yaygın bir şekilde rastlanilmaktadır. Bu şekilde elde edilmiş verilerin analiz edilmelerinde yaygin olarak kullanilan istatistik teknikler; $\chi^{2}$-istatistiği, Fisher'in Kesin Olasilık Hesaplanması, Gistatistiği ve Oran testi (Z-testi) dir. Ancak bu istatistik tekniklerinin kullanilabilmeleri bazi şartlara bağlı olup. çoğu kez bu istatistiğin gerektirdiği şartlar sağlanamamakta yada bu şartlar sağlansa bile elde edilen bilgi çok genel kalmakta ve sonuçların yorumlanmasında bazı gúçlüklerle karșilașılabilmektedir. Mesela bu tür veriler, iki yönlö tablo haline getirildikten sonra $\chi^{2}$. istatistiği ile analiz edilebilmesi, iki yönlü tablonun her bir hücresindekj beklenen frekanslarının en az 5 olması halinde güvenilir sonuçlar vermektedir. Bóylece, üzerinde durulan özellik ya da özellikler bakımından elde edilen bilgi kaybının az olması sağlanabilmektedir. Diğer yandan, oluşturulan iki yönlù tablonun bütün hücrelerinde beklenen frakansların 5 ve daha yukarısında olması durumunda bile elde edilen bilgi sadece satır değişkeni ile sütun değişkeninin birbirinden bağımsız olup olmadığına dair olup, oldukça yüzeysel bir bilgi vermektedir. Halbuki bir çok durumda araştırıcı, sadece satır ve sütun déğişkeni arasında bir bağımliliğın olup olmadığını değil, aymı zamanda hem her bir değişkenin kendi seviyeleri (alt kategori) içindeki hem de değişkenlerin karşıliklı olarak seviyeleri arasındaki ilișkilerle ilgilenebilir. Bu durumda araştırıcının $\chi^{2}$-istatistiği ile amacına ulaşması oldukça zordur. Dig̉er yandan iki yönla tablonun hücrelerindeki beklenen frekansların 5 'in altına düşmesi durumunda söz konusu tablonun analizi için, iki yönlü tablonun çeşitli $2 \times 2$ tablolarına dönüștürülerek Fisher'in Kesin Olasilik Hesaplanması yaklașımı kullanılabilir. Ancak hücrelerdeki beklenen frekansiardan bir kaçının sıfır olması durumunda bu testin uygulanması da araştırıcıya pek bir yarar saǵlamayacaktır. Bu durumda G-istatistiğinin kullanıması düşünülebilir: Ancak söz konusu tablonun hücrelerinde bulunan sifir sayısı kadar serbestlik derecesinden düșüleceği için eide edilecek bilginin güvenilirliği azalır. Hatta bazı durumlarda serbestlik derecesinin negatif olması da muhtemeldir Boyle durumlar, bu testin kullanılabilirligini sinırlamaktadır. Kullanılması mümkün olan bir diğer teknik olan oran testı ise olasılikların $(0,1)$ açık aralığındaki durumlar için hesaplanabilic. Olasılığın tam olarak 1 veya 0 olması durumunda oran testi kullanilamaz. Sifir frekansli hücrélerin olmasi durumunda da oran testinin kullanilması ile elde edilecek sonuclar yanilticı olurlar (Winer 1971, Snedecor ve Cochran 1980, Düzgüneș ve ark 1993)

\footnotetext{
'Ankara Univ Ziraat Fak. Zootekni Bölümu-Ankara
}

${ }^{2}$ Ankara Univ Çankir Orman Fakültesi-Cankin 
Uyum analizi (CA) kategorik bir şekilde elde edilmiş yada elde edildikten sonra kategorize edilerek iki yönlü table haline getirimiş verilerin hem satir ve sütun đeğișkenleri arasındaki ilişkilerin hem de her değișkenin kendi seviyeleri (alt kategorileri) arasindaki ilișkilerin açikłanmasına yardımcı olan ve aynı zamanda bu illş̧ilerin doş̧ok boyutlu bir uzayda grafik olarak da gösterilerek elde edilen sonuçlarin görsel olarak degerlendirilmesine imkan sağlayan bir tekniktir. Bu teknik, Çokiu uyum analizi (Optimal scaling), Temel Bileşenier Analizi ve Faktör Analizi ile ilișkili bir tekniktir. Bu tekniklerden Çoklu uyum analizi, Uyum Analizinin genel halidir. Uyum Analizi, üzerinde durulan özellik yada ozellikler bakımından toplam varyasyonun parçalanmasında ve boyut indirgeme bakimindan Temel Bileşenler Analizine benzerlik göstermektedir. Temel Bileşenler Analizinde $X$ veri setindeki değiş̧enlerin, değişken sayısından daha az sayıda ve birbirinden bağımsız olan Temel Bileșenler elde edilebilidiği, yani boyut indirgeme yapilabillyorsa, benzer sekilde Uyum Analizinde de bir boyut indirgeme söz konusudur, Uyum Analizinde boyut sayısi. (satir sayısi-1) ya da (sütun sayisi-1)'den küçùk olanı kadardır. Uyum Analizinde üzerinde durulan özellik ya da ózellikler bakımından toplam varyasyonun olçúsó olarak kullanilan toplam değişim (inertia) değeri de Temel Bileşenler Aılizine benzer bir biçimde unsurlarına parçalanabiliti. Uyyum Analizinin Temel Bileșenler Analizinden en önemli farkilığı verilerin elde ediliş șekillerinden kaynaklanmaktadır. Uyum Analizinde, veriler ya doğrudan kategorik bir şekilde elde edilmekte ya da elde edildikten sonra kategorize edfilmektedir Buna karşılık Temel Bileșenler Analizinde ise veriler, ollçmek, tartmak veya analiz etmek suretiyle elde edilmektedir (Nishasito 1980, Andersen 1990 Devilles ve Karcher 1991).

Uyum Analizi tekniǵi, özellikle bilgisayar yazilimlarımn gelişmesiyle sosyal bilimler başta olmak üzere oldukç̧a yaygin bir şekilde kullanilmaktadır. Bunun sebepleri ise kısaca aşağıdaki şekilde sıralanabilir:

i. Bu tekniğin varsayımlandan bağımsız olmasi,

ii. Diğer alternatiflerine göre kategorik verilerin analiz. edilmesinde hem daha kolay hem de daha uygun olmasi,

iii. Bu metotla ayni zamanda ayni uzayda satir ve sütun değişkenleri arasindaki ceșitii ilișkilerin grafik alarak gösterilebilmesi nedeniyle, sonuçiann görsel olmasi ve kolayca yorumlanabilmesi.

iv. Uyum Analizi, alternatifleri olabilecek tek değişkenti veya çok değișkenli yöntemlere nazaran uygulanmasınin daha kolay olmasi, daha güvenilir bilgi elde edilebilmesi ve sonuçların daha geniş bir şekilde yorumlanmasina imkan sağlamasıdir (Devilles ve Karcher 1991, Maulman 1998)

Bunlardan hareketle Uyum Analizinin, sosyal bilimier dişındaki birçok bilim alaninda da çok rahatıkla kullanilabileceği söylenebilir, Çünkü, birçok konưa elde edilen veriler, kategorik nitelikteki verilerdir. Ozellikle biyolojik olaylarla ilgili çalışmaların birçoğunda durum böyledir. Mesela belirli bir zarartı türünün ölüm oranının. farklı doziardaki ilaçlara bağlı olup olmadiğinin araştirildığı dưumlarda, değişik Irklarından hayvan sayılarının bulunduklan bölgelere bağlı olup olmadıḡinin belirlenmesinde, belirli bir irkın döl verim ozellikleri uzerine belirli bir hormonun degisşik dozlarmm etkili olup olmadığının belirlenmesinde, değişik göllerde yzşayan balık türlerinin dağilımlarının bulundukları göllere bağlı olup olmadıklannın araştırımasında, çeșitli buğday veya arpa varyetelerinin yaprakçık sayılarınin "dağilımları arasında fark olup olmadığının belirlenmesinde, çeşitli mikroorganizma türlerinin genomlarinda bulunan adenin, guanin, cytosine ve timin amino asidi sayılari bakımından dağılımlanının araştırıması vb gibi çalıșmalarda Uyum Analizi tekniği çok rahatıkla kullanılabilir (Nishisato 1980, Greenacre 1984).

Bu calışmada, yukarıda bahsedilen tekniklere göre daha detayh bilgi verebilen, bu metotlarin yetersiz kaldikları durumlarda çok rahatıkla kullanilabilen vè herhangi bir on șarta gereksinim duymayan Uyum analizi(CA) tekniğinin ózellikle biyolojik olaylarła ilgiti çalışmalarda nasıl kullanılabileceği adım adım aniatilarak. bu metodun yukarıdaki alternatif tekriklerine göre ustúnlükleri ele alınmış ve sonuçarın nasıl yorumlanabileceği üzerinde durulmuștur.

\section{Materyal ve Yöntem}

Çailșmada, Uyum Analizi tekniğinin hesaplama adımlarıni gerçek bir ornekle göstermek üzere, Oztürk ve Dellai (1999) tarafindan "Border Leicester X Booroala (ff) $X$ Merinos Melezi Koyunlarda Anestrus Donemi Esnasinda Farkil Dozlarda PMSG Uygulamasmin Döl Verimi Uzerine Etkileri" ni araştırmak amaciyla yapmış oldukları çalışmada, PMSG dozu ile çeșitti dog̉um lipinde doğan kuzuların doḡumdan itibaren bir aylik yaşa kadar ölenlerinin sayılanın ilişkin iki yōnlä tablo materyal olarak kullanilmıştır.

Yöntemin hesaplama aşamalan "Minitab for Windows Version 12" Istatistik Paket Programı kullanilarak yapilmiştır.

Uyum Analizi, i seviyeli Z-değişikeni ile I seviyeli Wdeğisskenlerinin, kendi seviyeleri arasındaki ve içindeki liş̧ileri açiklamaya yardima olan bir tekniktir. Z değisskeninin seviyeleri $i$ adet satır ve $W$ deḡişkeninin seviyeleri de $j$ adet sutunda olmak uzere, her hangi bir $Z x$ W tablosu i x j boyutlu bir ikl yönlù tablo oluşturmaktadir. Bu tablonun her bir hücresindeki gözlenen frekanslan $f_{j j}$ ile, tablonun boyutunu $k=i \times$ j ile, satır toplamlarini $f_{i}$, sütün toplamiann $f_{j}$ ve toplam gözlem sayısıni da $N$ ile gösterirsek; I $x$ j boyutlu iki yönla tablanun Uyum Analizi tekniği lle analizi ( $Z$ değișkeni 2 ve $W$ değișkeninin de 3 seviyesi olduğu varsayilırsa) aşağıdaki işlem sıraları takip edilerek yapilir:

1. Tablonum her bir hücresindeki gözlenen Irekanslarin marjinal gözlenme frekanslar bulunur.(Satir ve sutun profilleri bulunur) 


\begin{tabular}{|l|l|l|l|l|}
\hline & $W_{1}$ & $W_{2}$ & $W_{3}$ & $\Sigma$ \\
\hline$Z_{1}$ & $f_{11}$ & $f_{12}$ & $f_{13}$ & $f_{1}$ \\
\hline$Z_{2}$ & $f_{21}$ & $f_{22}$ & $f_{23}$ & $f_{2}$ \\
\hline$\Sigma$ & $f_{1}$ & $f_{2}$ & $f_{3}$ & $f_{1}$ \\
\hline
\end{tabular}

\begin{tabular}{|l|l|l|}
\hline \multicolumn{3}{|c|}{ Satir profilleri } \\
\hline$f_{11} / f_{1}$ & $f_{12} / f_{1}$ & $f_{13} / f_{1}$ \\
\hline$f_{21} / f_{2}$ & $f_{22} / f_{2}$ & $f_{23} / f_{2}$ \\
\hline & & \\
\hline
\end{tabular}

\begin{tabular}{|l|l|l|}
\hline \multicolumn{3}{|c|}{ Sütun profilleri } \\
\hline$f_{11} / f_{1}$ & $f_{12} / f_{2}$. & $f_{13} / f_{3} 3$ \\
\hline$f_{21} / f_{1} 1$ & $f_{22} / f_{2}$ & $f_{23} / f_{3}$ \\
\hline & & \\
\hline
\end{tabular}

2. Bir satır ve sütunun seviye oranlari (kategori oranlari), söz konusu satırın, satır toplamının genel toplama ve söz konusu sütunun sütun toplamınin da genel

\begin{tabular}{|c|c|c|c|}
\hline & & & Satır ağırlığı \\
\hline$f_{11}$ & $f_{12}$ & $f_{13}$ & $f_{1} / \mathrm{N}$ \\
\hline$f_{21}$ & $f_{22}$ & $f_{23}$ & $f_{2} / N$ \\
\hline
\end{tabular}

3. Kategorilerin birbirlerine göre uzaklıkları hesaplanır. Bu işlem, farklı yaklaşımlarla yapılabilmektedir. Mesela; $\chi^{2}$-uzaklığı veya öklit uzaklıkları gibi. Bu çalışmada $\chi^{2}$-uzaklıkları esas alınmıştır. Bu uzaklıklar; $\chi_{\mathrm{d}_{i j}}^{2}=\frac{\left(f_{i j}-f_{i j}\right)^{2}}{f_{i j}}$ şeklinde hesaplanmaktadır. Bu ifadede; $\mathrm{fij}_{\mathrm{j}}$ : her bir hücredeki gözlenen frekansları, $\mathrm{f}_{i j}$ : her bir hücredeki beklenen frekansları göstermektedir. $f_{i j}=f_{i}, f_{i} / \mathrm{N}$ şeklinde hesaplanır.

4. $\chi^{2}$-uzaklıklarından yararlanilarak tablonun toplam $\chi^{2}$-değeri; $\chi^{2}=\Sigma \Sigma \chi^{2}$ ij şeklinde hesaplanır.

Hesaplanan $\chi^{2}$ değeri, toplam gözlem sayısına bölünerek tablonun genel değişim (inertia) değeri bulunur.

6. Elde edilen genel deg̃işim deg̃erinden yararlanılarak, tablodaki her bir deg̈işkene ilişkin kategorilerinin birbirlerinden olan uzaklıklarının daha az boyutla (eksenle) açıklanip açıklanamayacağı hususunda bir fikir edinilebilir. Toplam değişim deg̃eri (ayni zamanda öz-değerler olarak da bilinmektedir) her bir boyut için, satır profilleri ile sütun profilleri arasındaki kanonik korelasyon olarak adlandirilan tekil değerin (singular value) karesidir. Toplam değişim değeri, aslinda tablodaki varyansın bir ölçüsüdür. Bu değerden yararlamlarak ele alınan tablodaki varyasyonun kaç boyutla açıklanabileceği belirlenir. Bunun için toplam değış̧im değerinin her bir boyuttaki (eksendeki) payını yani, her bir boyutun açıklayabildiği varyasyon payının bulunması gerekir. Bunun için, önce tekil değerlerin (singular values) bulunması gerekmektedir. Tekil değerlerin bulunması aşağıdaki adimlar izlenerek yapilabilmektedir.

6.1 Oluşturulan iki yönlü tablo i x j boyutlu bir matrise aktarilır $\left(F_{i j}\right)$,

$$
F=\left[\begin{array}{lll}
f_{11} & f_{12} & f_{13} \\
f_{21} & f_{22} & f_{23}
\end{array}\right]
$$

6.2. Satır ve Sütun toplamlarının yer aldığı $r$ ve $c$ vektörleri bulunur. Bunlar;

$r=F v$ ve $c=u^{\prime} F(u, v$, elemanlari 1 olan vektörler olup, $u ; r \times 1, v ; c x 1$ boyutludur) şeklinde elde edilebilir. toplama bölünmesi sonucu elde edilen ve satır veya sütünün ağırlık payı (mass) olarak adlandırılan satır ve sütun kategori oranları bulunur.

\begin{tabular}{|c|c|c|c|}
\cline { 2 - 4 } \multicolumn{1}{c|}{} & \multicolumn{3}{|c|}{} \\
\cline { 2 - 4 } \multicolumn{1}{c|}{} & $f_{11}$ & $f_{12}$ & $f_{13}$ \\
\cline { 2 - 4 } & $f_{21}$ & $f_{22}$ & $f_{23}$ \\
\hline Sütun ağırlıḡı & $f_{1} / \mathrm{N}$ & $f_{2} / \mathrm{N}$ & $f_{3} / \mathrm{N}$ \\
\hline
\end{tabular}

$$
r=\left[\begin{array}{l}
f_{1} \\
f_{2}
\end{array}\right] \quad c=\left[\begin{array}{l}
f_{1} \\
f_{2} \\
f_{3}
\end{array}\right]
$$

$6.3 \mathrm{r}$ ve $\mathrm{c}$ vektörleri $D_{r}=\operatorname{diag}(r)$ ve $D_{C}=\operatorname{diag}(c)$ şeklinde kōşegen matrise dönüştūrülūrler.

$$
D_{1}=\left[\begin{array}{cc}
f_{1} & 0 \\
0 & f_{2}
\end{array}\right] \quad D_{c}=\left[\begin{array}{ccc}
f_{1} & 0 & 0 \\
0 & f_{2} & 0 \\
0 & 0 & f_{3}
\end{array}\right]
$$

6.4. F matrisinin Uyum analizi sonuçlarının daha az sayıdaki boyutla gösterimini elde etmek için, gerekli olan her bir satırin ve her bir sûtunun koordinat eksenindeki koordinatlarınin belirlenmesini sağlayacak $X$ ve $Y$ matrislerinin bulunması gerekir. Bunun için;

6.4.1. F'nin $X$ matrisi şeklindeki gösteriminin elde edilmesi gerekir. Bunu elde etmek için, $F, D_{r}$ ve $D_{c}$ matrislerinden yararlanilarak; $E=D_{f}^{-1 / 2} F_{c}^{-1 / 2}$ elde edilir. Bu E matrisi, toplam değişim değerinin her bir boyuttaki açıklanabilen varyasyon payını gösterecek olan boyutsal değişim değerlerinin elde edilmesinde kullanilir. Bunun için de $\mathrm{E}$ matrisinin, tekil değere ayrıştırma (Singular Values Decomposition=svd) yöntemi kullanılarak $(K, \Lambda, V)=\operatorname{svd}(E)$ şeklinde ayrıştırilmasi gerekir, Bu işlem aşağıdaki adımlar izlenerek yapılır.

\subsubsection{1. $A=E^{\prime} E$ kare matrisi bulunur.}

6.4.1.2. A matrisinin öz-değerleri bulunur $\left(|A-\lambda| \mid=0^{\prime}\right.$ dan yararlanilarak),

6,4,1.3. Her bir öz-deḡere karşilık gelen öz-vektörler bulunur,

6.4.1.4. Öz-vektörler yardımıyla $V$ matrisi, özdeğerlerin kareköklerinin köşegen matrise dönüştürülmesi ile de $\Lambda$ matrisi elde edilir,

6.4.1.5. $\mathrm{K}$ matrisinin her bir sütununun oluşturduğu $\mathrm{k}_{\mathrm{i}}$ vektörleri;

$$
\left.k_{i}=\frac{1}{\sqrt{\lambda_{i}}} E V_{i} \text { şeklinde elde edilir ( } v_{i}, i . \text { öz-vektördür }\right)
$$


6.4.2. Satır profilleri in apsislerini ve Sülun profillerinin ordinatlarını gösteren $X$ ve $Y$ matrisleri;

$$
\mathrm{X}=\mathrm{N}^{1 / 2} \mathrm{D}_{r}^{-T / 2} \mathrm{~K} \Lambda \quad \mathrm{Y}=\mathrm{N}^{1 / 2} \mathrm{D}_{\mathrm{c}}^{-1 / 2} \mathrm{V \Lambda} \quad \text { seklinde }
$$

kolayca hesaplanir.

Yukarıdaki $K$ ve $V$ matrisleri $K^{\prime} K=V^{\prime} V=1$ șartinı sağlamalıdirlar.

7. $X$ ve $Y$ matrislerinin elemanlarından yararlanilarak, satır ve sütun değişkenleri arasındaki ilişkiler grafiksel olarak gösterilebilir. Bu grafikte, her değişkenin her seviyesi koordinat sisteminde ayfi bir nokta olarak temsil edilir. Bu noktalardan bir birine yakın olanlarının, Uzerinde durulan ozellikler bakimindan birbirlerine benzer olduklari. birbirinden uzak olanların da farklı oldukları anlaşılı. Aynı zamanda, çizilen grafikte satır değişkeninin seviyelerinin $X$-ekseni boyunca sıralanmaları yani $X$-ekseni üzerinde yada ona çok yakın olmaları, satır değişkeninin seviyelerinin üzerinde durulan özellik bakımindan birbirlerinden bağımsız oldukları, dolayısıyla birbirlerini etkilemedikleri anlamına gelmektedir. Benzer durum, sütun değişkenleri için de Y-ekseni baz alinarak geçerlidir.

\section{Bulgular ve Tartışma}

Çalıșmada kullanilan iki yönlü tablo, Çizelge 1 'de verilmiştir.

Çizelge 1. PMSG uygulanan ve uygulanmayan koyuniarda doğum-1, ay arasında ölen kuzu sayılan "

\begin{tabular}{|c|c|c|c|c|c|}
\hline $\begin{array}{c}\text { PMSG } \\
\text { dozu (IU) }\end{array}$ & \multicolumn{4}{|c|}{ W faktôrü } & Toplam \\
\hline$z$ & Tekiz & Tkiz & Uçüz & Dórdüz & \\
\hline 0 & 1 & 1 & 0 & 0 & 2 \\
\hline 250 & 3 & 6 & 0 & 0 & 9 \\
\hline 300 & 7 & 10 & 12 & 4 & 33 \\
\hline 400 & 4 & 3 & 11 & 0 & 18 \\
\hline 600 & 0 & 4 & 6 & 2 & 12 \\
\hline Toplam & 15 & 24 & 29 & 6 & 74 \\
\hline
\end{tabular}

Çizelge 2. Satır profilleri ve satir ağırlik oranlafı
PMSG'nin değişik dozlarinin ( $Z$ faktörú) doğumdan itibaren bir aylik yaşa kadar ölen kuzuların doğum tipine (W faktörü) etkisinin Uyum Analizi (Correspondance Analysis) tekniği ile araştırilması amacıyla, W faktörünün 4 (Tekiz, Ikiz, Üçüz ve Dördüz) seviyesi ile $Z$ fakț̈rünün 5 ( 0 IU, $250 \mathrm{IU}, 300 \mathrm{IU}, 400 \mathrm{IU}$ ve $600 \mathrm{IU}$ ) seviyesinin ele alındiğı böyle bir çalışmada, eğer $\chi^{2}$-testi, G-Istatistiği ve Fisher'in Kesin Olasilik Hesaplanması test tekniklerinden yararlanilirsa, $W$ faktörünün seviyelerini $Z$ faktörünün seviyelerinden bağımsız ołup olmadıklarına karar verilebilir. Fakat bu karar araştırıcınin asıl araştırmak istediği konuya bir cevap teșkil etmez. Çünkŭ araștıııı W faktörünün hangi seviyesinin $Z$ faktörünün hangi seviyesi üzerine etki ettiğini merak etmektèdir. Bu amacını gerçekleştirmek üzere, W faktörünün her bir seviyesinde Z faktörünün seviyelerine ait oranları karșilaștirarak veya $Z$ faktörünün her bir seviyesinde $W$ faktörünün seviyelerine ait oranları ikişer ikişer karşıllaştırarak ulaşmak isteyebilit. Ancak bu durumda da, ya gözlemlerin aynı populasyonlardan alınmış rastgele örneklerden elde edilmiş olduğunu, ya da söz konusu gözlemlerin farklı populasyonlardan alınmış rastgele ömekler olduklarını varsaymak durumundadir. Bu varsayimlarin her ikisi de her zaman ele alınan orneklerin yapısına uygun olmayabilmektedir, Bu nedenle varılan hükümlerde bir miktar gerçek durumdan uzaklaşma olabilmektedir. Bir bașka sakıncalı durum da, gözlenen oranların 1 veya 0 çıkması halinde ortaya çıkmaktadir. Çünkü oranın 1 veya 0 çıkmasi oran testinin kullanilmasını kısıtlar. Bu sakıncalan önlemek üzere, herhangi bir varsayım gerektirmeyen ve araştırıcinın amacina da uygun olan, Uyum Analizi tekniği rahatlıkla kullanılabilir. Bu teknik araștricıya daha fazla bilgi verebileceg̃i gibi yorumlamalarını da daha kolay yapmasına imkan vermektedir.

Çizelge 1'deki verilerin Uyum Analizi tekniği ile irdelenme aşamaları aşağıdaki gibidir.

i) Iki yönlü tablonun satır, sútun profilleri ve ağrrlik oranları bulunur. Bu değerler sırasılyia Çizelge 2 ve 3 'de verilmiş̧tir.

\begin{tabular}{|c|c|c|c|c|c|}
\hline \multirow{2}{*}{$\begin{array}{l}\text { Doz } \\
\text { (IU) }\end{array}$} & \multicolumn{4}{|c|}{ Satır profilleri } & \multirow{2}{*}{ Satır ağırlik oranı } \\
\hline & Tekiz & Tkiz & Ūçüz & Dórdüz & \\
\hline 0 & $1 / 2=500$ & $1 / 2=.500$ & $0 / 2=000$ & $0 / 2=000$ & $2 / 74=027$ \\
\hline 250 & $3 / 9=333$ & $6 / 9=667$ & $0 / 9=.000$ & $0 / 9=.000$ & $9 / 74=122$ \\
\hline 300 & $7 / 33=212$ & $10 / 33=, 303$ & $12 / 33=364$ & $4 / 33=121$ & $33 / 74=.446$ \\
\hline 400 & $4 / 18=222$ & $3 / 18=.167$ & $11 / 18=.611$ & $0 / 18=000$ & $1 8 \longdiv { 7 4 } = . 2 4 3$ \\
\hline 600 & $0 / 12=, 000$ & $4 / 12=.333$ & $6 / 12=.500$ & $2 / 16=.167$ & $12 / 74=.162$ \\
\hline
\end{tabular}

Çizelge 3. Sütun profilleri ve sütun ağırlık oranlari

\begin{tabular}{|c|c|c|c|c|}
\hline \multirow{2}{*}{ Doz (IU) } & \multicolumn{4}{|c|}{ Sütun profilleri } \\
\cline { 2 - 5 } & Tekiz & lkiz & Uçũz & Dördüz \\
\hline 0 & $1 / 15=0.067$ & $1 / 24=0.042$ & $0 / 29=0.000$ & $0 / 6=0.000$ \\
\hline 250 & $3 / 15=0.200$ & $6 / 24=0.250$ & $0 / 29=0.000$ & $0 / 6=0.000$ \\
\hline 300 & $7 / 15=0.467$ & $10 / 24=0.417$ & $12 / 29=0.414$ & $4 / 6=0.667$ \\
\hline 400 & $4 / 15=0,267$ & $3 / 24=0.125$ & $11 / 29=0.379$ & $0 / 6=0,000$ \\
\hline 600 & $0 / 15=0.000$ & $4 / 24=0.167$ & $6 / 29=0.207$ & $2 / 6=0.333$ \\
\hline Sütun ağirfik orani & $15 / 74=0.203$ & $24 / 74=0.324$ & $29 / 74=0.392$ & $6 / 74=0.081$ \\
\hline
\end{tabular}


ii) $\chi^{2}$-uzaklıkları $x_{d_{i j}}^{2}=\frac{\left(f_{i j}-f_{i j}^{\prime}\right)^{2}}{f_{i j}^{+}}$ifadesine göre hesaplanır (Çizelge 4).

Çizelge 4. $\chi^{2}$-Uzaklıkları

\begin{tabular}{|c|c|c|c|c|c|}
\hline Doz (IU) & Tekiz & Íkiz & Üçüz & Dördüz & Toplam \\
\hline 0 & 0.872 & 0.190 & 0.784 & 0.162 & 2.008 \\
\hline 250 & 0.758 & 3.252 & 3.527 & 0.730 & 8.267 \\
\hline 300 & 0.014 & 0.046 & 0.067 & 0.655 & 0.783 \\
\hline 400 & 0.034 & 1.380 & 2.207 & 1.459 & 5.080 \\
\hline 600 & 2.432 & 0.003 & 0.358 & 1.084 & 3.877 \\
\hline Toplam & 4.110 & 4.871 & 6.943 & 4.091 & 20.016 \\
\hline
\end{tabular}

Toplam $\chi^{2}$ değeri, (5-1)x(4-1)=12 serbestlik dereceli $\chi^{2}$ tablo değeri ile karşilaştırilırsa, Doğum-1ay arasında ölen kuzuların doğum tiplerinin koyunlara uygulanan PMSG dozlarından bağımsız oldug̉u kararı verilebilir. Ancak, $\chi^{2}$ testi ile varılan bu karar pek güvenilir değildir. Çünkü, $\chi^{2}$-testinin yapilabilmesi, ancak her bir hücredeki beklenen frekansların 5 ve daha büyük olması halinde güvenilirdir. Halbuki bu örnekte 15 hücrede beklenen frekans 5 ten az, 6 hücrede de 1'den daha az bulunmuştur. Kaldı ki bu sonuç güvenilir olsa bile, araştırıcının asıl merak ettiği soruya yani, "Kuzularda ölüm oranının PMSG dozlarına göre değişip değişmediğini, eğer değişiyorsa hangi dozda en az olmaktadır?" sorularına cevap vermekten uzaktır. Benzer durum GIstatistiği için de geçerlidir. Eğer, kuzuların ölüm oranları PMSG dozu seviyelerine göre ikişer ikişer karşılaştırılmak istense (iki oranın karşılaştırılmasına ilişkin Z-Testi kullanılarak), bu örnekte söz konusu testi kullanmak da pek mümkün değildir. Çünkü oranların bir kısmı O'dır. Öztürk ve Dellal (1999) bu hükümden hareketle, sadece satır ağırlık oranlarına göre PMSG dozlarını karşılaştırmakla yetinmiş, doz ve doğum tiplerine göre ölüm oranları hakkında bilgi edinememişlerdir. Halbuki Uyum Analizi ile durumun gerçekten böyle olup olmadığı daha doğru bir yaklaşımla ortaya konulabilir.

iii) $W \times Z$ iki yönlü tablosu $F$ matrisine aktarilır ve bundan yararlanarak, Satır ve sütun toplamlarını içeren $D_{r}$ ve $D_{c}$ matrisleri oluşturulur.

$$
\begin{aligned}
& F=\left[\begin{array}{llll}
1 & 1 & 0 & 0 \\
3 & 6 & 0 & 0 \\
7 & 10 & 12 & 4 \\
4 & 3 & 11 & 0 \\
0 & 4 & 6 & 2
\end{array}\right] \\
& D_{c}=\left[\begin{array}{cccc}
15 & 0 & 0 & 0 \\
0 & 24 & 0 & 0 \\
0 & 0 & 29 & 0 \\
0 & 0 & 0 & 6
\end{array}\right]
\end{aligned}
$$

iv) E matrisinin bulunması,

$$
\begin{aligned}
& E=D_{r}^{-1 / 2} F_{c}^{-1 / 2}=\left[\begin{array}{ccccc}
2 & 0 & 0 & 0 & 0 \\
0 & 9 & 0 & 0 & 0 \\
0 & 0 & 33 & 0 & 0 \\
0 & 0 & 0 & 18 & 0 \\
0 & 0 & 0 & 0 & 12
\end{array}\right]^{-1 / 2}\left[\begin{array}{cccc}
1 & 1 & 0 & 0 \\
3 & 6 & 0 & 0 \\
7 & 10 & 12 & 4 \\
4 & 3 & 11 & 0 \\
0 & 4 & 6 & 2
\end{array}\right] \\
& {\left[\begin{array}{cccc}
15 & 0 & 0 & 0 \\
0 & 24 & 0 & 0 \\
0 & 0 & 29 & 0 \\
0 & 0 & 0 & 6
\end{array}\right]^{-1 / 2}=\left[\begin{array}{lll}
.182574 .144338 .000000 .000000 \\
.258199 .408248 .000000 .000000 \\
.314627 .355335 .387905 .284268 \\
.243432 .144338 .481457 .000000 \\
.000000 .235702 .321634 .235702
\end{array}\right.}
\end{aligned}
$$

v) $A=E^{\prime} E$ matrisinin bulunması,

$$
\begin{aligned}
A=E^{\prime} E & =\left[\begin{array}{lllll}
182574 & .258199 & .314627 & .243432 & .000000 \\
144338 & .408248 & .355335 & .144338 & .235702 \\
.000000 & .000000 & .387905 & 481457 & .321634 \\
.000000 & .000000 & .284268 & .000000 & .235702
\end{array}\right] \\
& {\left[\begin{array}{lllll}
182574 & .144338 & .000000 & .000000 \\
.258199 & .408248 & .000000 & .000000 \\
314627 & .355335 & .387905 & .284268 \\
.243432 & .144338 & .481457 & .000000 \\
.000000 & .235702 & .321634 & .235702
\end{array}\right] } \\
& =\left[\begin{array}{llll}
.258249 & .278696 & .239247 & .089438 \\
278696 & .390152 & .283138 & 156566 \\
.239247 & .283138 & .485719 & .186079 \\
.089438 & .156566 & .186079 & .136364
\end{array}\right]
\end{aligned}
$$

vi) Tekil değeriere ayrıştırma (singular values decomposition) metodu ile $A$ matrisinden hareketle, $K, \wedge$ ve $\mathrm{V}$ matrislerinin bulunması,

vi.1. A matrisinin öz-değerlerinin bulunması,

$|A-\lambda|=0=\left|\begin{array}{rrrr}.258249 \lambda & 278696 & .239247 & .089438 \\ 278696 & 390152 \lambda & .283138 & 156566 \\ .239247 & 283138 & .485719 \lambda & 186079 \\ .089438 & 156566 & .186079 & .136364 \lambda\end{array}\right|=0$

determinantından elde edilecek 4.dereceden denklemin çözülmesi ile, $\lambda_{1}=1.0000000, \lambda_{2}=1781152, \lambda_{3}=.0767465$ ve $\lambda_{4}=0156219$ öz-değerleri elde edilir. 
vi.2. Öz-değerlerin k arekökleri alınıp köşegen matrise dönüştürülerek $\Lambda$ matrisı elde edilir,

$$
\begin{aligned}
\Lambda & =\left[\begin{array}{cccc}
\sqrt{1.0000000} & 0 & 0 & 0 \\
0 & \sqrt{.1781152} & 0 & 0 \\
0 & 0 & \sqrt{.0767465} & 0 \\
0 & 0 & 0 & \sqrt{.0156219}
\end{array}\right] \\
& =\left[\begin{array}{cccc}
1.0000000 & 0 & 0 & 0 \\
0 & .4220370 & 0 & 0 \\
0 & 0 & .2770315 & 0 \\
0 & 0 & 0 & .1249874
\end{array}\right]
\end{aligned}
$$

vi.3. Öz-değerlere karşılık gelen öz-vektörler;

$$
\lambda_{1}=1.0000000 \text { için } v_{1}=\left[\begin{array}{l}
-.450225 \\
-.569495 \\
-.626013 \\
-.284747
\end{array}\right] \text {, }
$$$$
\lambda_{2}=.1781152 \text { için } v_{2}=\left[\begin{array}{r}
-.406725 \\
-.549569 \\
.702350 \\
.198122
\end{array}\right] \text {, }
$$$$
\lambda_{3}=.0767465 \text { için } v_{3}=\left[\begin{array}{r}
-.514982 \\
.318345 \\
-.261201 \\
.751814
\end{array}\right] \text { ve }
$$$$
\lambda_{4}=.0156219 \text { için } v_{4}=\left[\begin{array}{r}
-605529 \\
.521829 \\
.215839 \\
-.560752
\end{array}\right] \text { olarak bulunduktan }
$$

sonra $V$ matrisi;

$$
V=\left[\begin{array}{rrrr}
-.450225 & -.406725 & -.514982 & -.605529 \\
-.569495 & -.549569 & .318345 & .521829 \\
-.626013 & .702350 & -.261201 & .215839 \\
-.284747 & .198122 & .751814 & -.560752
\end{array}\right]
$$
şeklinde elde edilir.

vi.4. $K$ matrisini elde etmek üzere $k_{i} \quad(i=1,2,3,4)$ vektörleri;

$$
\begin{gathered}
k_{i}=\frac{1}{\sqrt{\lambda_{i}}} E v_{i} \text { ifadesi yardımıyla hesaplanır, } \\
k_{1}=\frac{1}{\sqrt{1.000000}}\left[\begin{array}{lllll}
.182574 & .144338 & .000000 & .000000 \\
.258199 & .408248 & .000000 & .000000 \\
.314627 & .355335 & .387905 & .284268 \\
.243432 & .144338 & .481457 & .000000 \\
.000000 & .235702 & .321634 & .235702
\end{array}\right]
\end{gathered}
$$

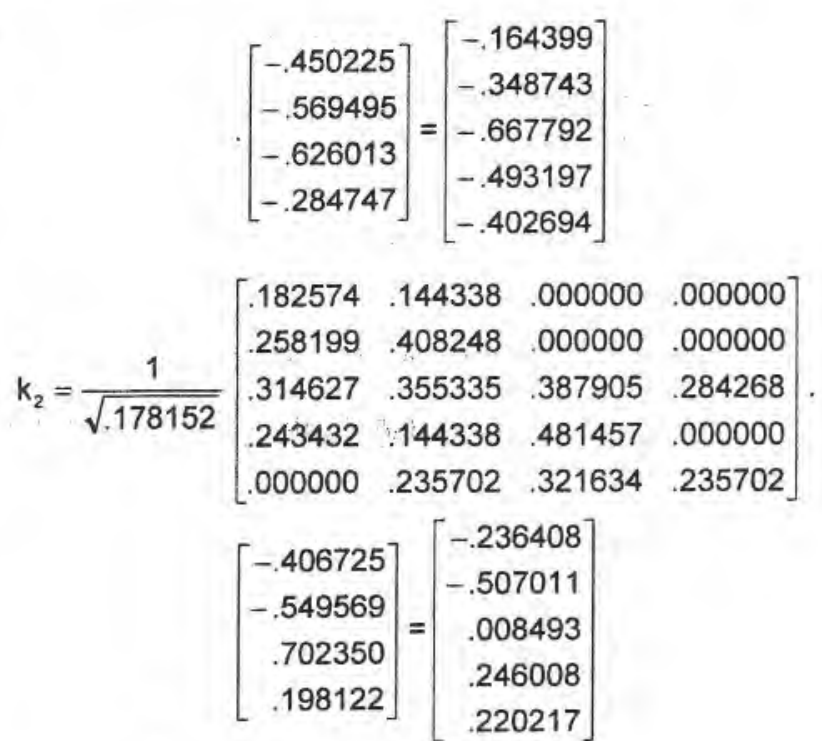

$k_{3}=\frac{1}{\sqrt{.0767465}}$

$$
\begin{array}{r}
{\left[\begin{array}{rrrr}
.182574 & .144338 & .000000 & .000000 \\
.258199 & .408248 & .000000 & .000000 \\
.314627 & .355335 & .387905 & .284268 \\
.243432 & .144338 & .481457 & .000000 \\
.000000 & .235702 & .321634 & .235702
\end{array}\right]} \\
{\left[\begin{array}{r}
-.514982 \\
.318345 \\
-.261201 \\
.751814
\end{array}\right]=\left[\begin{array}{r}
-.091335 \\
-.005707 \\
.120621 \\
-.389809 \\
.319620
\end{array}\right]}
\end{array}
$$$$
k_{4}=\frac{1}{\sqrt{.0156219}}
$$$$
\left[\begin{array}{llll}
.182574 & .144338 & .000000 & .000000 \\
.258199 & .408248 & .000000 & .000000 \\
.314627 & .355335 & .387905 & .284268 \\
.243432 & .144338 & .481457 & .000000 \\
.000000 & .235702 & .321634 & .235702
\end{array}\right] \text {. }
$$$$
\left[\begin{array}{r}
-.605529 \\
.521829 \\
.215839 \\
-.560752
\end{array}\right]=\left[\begin{array}{r}
-.099663 \\
.160349 \\
-.228464 \\
.090037 \\
.170413
\end{array}\right]
$$

şeklinde bulunan $\mathrm{k}_{\mathrm{i}}$ vektörlerinden yararlanılarak $\mathrm{K}$ matrisi oluşturulur, 


$$
\mathrm{K}=\left[\begin{array}{rrrr}
-.164399 & -.236408 & -.091335 & -.099663 \\
-.348743 & -.507011 & -.005707 & .160349 \\
-.667792 & .008493 & .120621 & -.228464 \\
-.493197 & .246008 & -.389809 & .090037 \\
-.402694 & .220217 & .319620 & .170413
\end{array}\right]
$$

$\mathrm{K}^{\prime} \mathrm{K}=\mathrm{V}^{\prime} \mathrm{V}=\mathrm{l}$ olduğuna dikkat edilmelidir.

vi.5. Satır ve sütun değişkenlerinin koordinatlarının belirlenmesi,

$$
\begin{aligned}
& X= N^{1 / 2} D_{f}^{-1 / 2} K \Lambda \\
& X=74^{1 / 2}\left[\begin{array}{ccccc}
2 & 0 & 0 & 0 & 0 \\
0 & 9 & 0 & 0 & 0 \\
0 & 0 & 33 & 0 & 0 \\
0 & 0 & 0 & 18 & 0 \\
0 & 0 & 0 & 0 & 12
\end{array}\right] \\
& {\left[\begin{array}{ccccc}
-.164399 & -.236408 & -.091335 & -.099663 \\
-.348743 & -.507011 & -.005707 & .160349 \\
-.667792 & .008493 & .120621 & -.228464 \\
-.493197 & .246008 & -.389809 & .090037 \\
-.402694 & .220217 & .319620 & .170413
\end{array}\right] . } \\
& {\left[\begin{array}{ccccc}
1.0000000 & 0 & 0 & 0 \\
& 0 & .4220370 & 0 & 0 \\
& 0 & 0 & .2770315 & 0 \\
& 0 & 0 & 0 & .1249874
\end{array}\right] } \\
&=\left[\begin{array}{ccccc}
-1 & -.60690 & -.15391 & -.07577 \\
-1 & -.61357 & -.00453 & .05747 \\
-1 & .00537 & .05004 & -.04276 \\
-1 & .21051 & -.21896 & .02282 \\
-1 & .23080 & .21988 & .05289
\end{array}\right]
\end{aligned}
$$

ve $Y=N^{1 / 2} D_{c}^{-1 / 2} V \Lambda$

$Y=74^{1 / 2}\left[\begin{array}{cccc}15 & 0 & 0 & 0 \\ 0 & 24 & 0 & 0 \\ 0 & 0 & 29 & 0 \\ 0 & 0 & 0 & 6\end{array}\right]^{-1 / 2}$

$\left[\begin{array}{rrrr}-.450225 & -.406725 & -.514982 & -.605529 \\ -.569495 & -.549569 & .318345 & .521829 \\ -.626013 & .702350 & -.261201 & .215839 \\ -.284747 & .198122 & .751814 & -.560752\end{array}\right]$

$\left[\begin{array}{cccc}1.0000000 & 0 & 0 & 0 \\ 0 & .4220370 & 0 & 0 \\ 0 & 0 & .2770315 & 0 \\ 0 & 0 & 0 & .1249874\end{array}\right]$

$$
=\left[\begin{array}{rrrr}
-1 & -.38126 & -.31688 & -.16810 \\
-1 & -.40727 & .15486 & .11453 \\
-1 & .47350 & -.11559 & .04309 \\
-1 & .29365 & .73144 & -.24614
\end{array}\right]
$$

olarak bulunurlar.

Gerek $X$ matrisinin gerekse $Y$ matrisinin ilk sütunu daima 1'lerden oluşur. Bunun sebebi $\lambda_{1}=1$ olacak şekilde ayrıștırma ișleminin yapılmasıdır. Dolayısıyla, $X$ ve $Y$ matrislerinin ilk sütunlan deg̈erlendirmeye alınmazlar.

vi.6. Yukarıda bulunan sonuçlar yardımıyla Uyum analizi tekniğine esas teşkil eden iki yönlü tablonun, analiz tablosu Çizelge 5'deki gibi oluşturulur. Bu analiz tablosuna dikkat edilirse, $\chi^{2}$ istatistiğinin önemsiz oldug̃u görülebilir. Dolayısıyla satır ve sütun değişkenlerinin birbirlerinden bağımsız olduğu söylenir. Bundan dolayı satır ve sütun değişkenlerinin etkilerine pratikte genellikle

\begin{tabular}{|c|c|c|c|c|c|c|c|}
\hline \multirow[b]{2}{*}{ Boyutiar } & \multirow[b]{2}{*}{ Tekil değer } & \multicolumn{3}{|c|}{$\begin{array}{l}\text { Boyutların toplam değissim değerini } \\
\text { açıklama oranları }\end{array}$} & \multirow[t]{2}{*}{$\begin{array}{l}\chi^{2} \text {-Deḡeri } \\
\text { (12 S.D.'li) }\end{array}$} & \multirow[t]{2}{*}{$\begin{array}{c}\text { Onemlilik } \\
\text { düzeyi }\end{array}$} & \multirow[t]{2}{*}{$\begin{array}{c}\text { Kanonik } \\
\text { korelasyoniar }\end{array}$} \\
\hline & & Boyutlardaki & $\begin{array}{c}\text { Açıklama } \\
\text { payı }\end{array}$ & $\begin{array}{l}\text { Eklemeli } \\
\text { pay }\end{array}$ & & & \\
\hline 1 & .4220370 & .1781152 & 6585066 & .6585066 & 20.016 & .067 & -.086 \\
\hline 2 & .2770315 & .0767465 & 2837382 & 9422448 & & & \\
\hline 3 & 1249874 & 0156219 & .0577555 & 1.000000 & & & \\
\hline & Toplam & 2704835 & & & & & \\
\hline
\end{tabular}
ayn ayrı bakılmaktadir. Ancak Uyum Analizi tekniğinde hem sadece satır deḡișkeni hem de sadece sütün değişkeni kendi seviyeleri arasındaki farkıllıklar bakımından ele alındıkları gibi, ikisi birlikte de değerlendirilebilmektedir.

Çizelge 5. Uyum analizi tablosu

Değişkenlerin birbirlerinden bağımsız ( $P>0.05$ olması halinde) olmalarına rağmen hücrelerdeki gözlem sayılarının düşüklüğü böyle bir incelemeyi gerekli kıımaktadır. Çünkü toplam gözlem sayısının artırııması halinde değişkenlerin birbirine bağımlı çıkması muhtemeldir. Bu durumda araştırıcı iki değişkenin interaksiyonu (satır ve sütun değişkenlerinin karşılıklı etkileşimi) hakkında da bilgi sahibi olmak ister. Satır ve sütun deḡişkenleri ilk önce ayrı ayrı değerlendirilecek olursa; 
Sadece sütun deği,keni ya'i doğum tipi göz önüne alınarak bir karşılaştırma yapııdığında (Şekil 1):

1. 300 IU PMSG dozunun en çok üçüzlerde ölüm frekansını artırdığını,

2. Dördüzlerde ölüm frekanslarının yine 300 IU PMSG uygulamasında en yüksek olduğu,

3. Ikizlerde 300 IU PMSG uygulamasının yaklaşık dördüzler kadar olduğu (çünkü, ikizlerin ve dördüzlerin 300 IU dozuna olan uzaklıkları hemen hemen aynıdır.),

4. 300 IU dozunun tekizlerde de ölüm frekansın etkilediğini söylemekle birlikte, diğer doğum tiplerine nazaran bu etkinin daha az olduğunu,

5. 250 IU dozunun hemen hiçbir doğum tipinde ölüm frekanslarına önemli bir etkisinin olmadığı,

6. 400 IU dozunun 300 IU dozundan daha az olmakla birlikte üçüzlerde ölüm frekanslarını etkilediğini,

7. 600 IU dozunun ise, en çok dördüzlerde ölüm frekansının artırdığını, buna karşılık en az tekizler üzerinde etkili olduğunu,

8. 0 IU dozunun sadece tekiz ve ikizlerde çok az bir etkiye sahip olduğunu (doğum tipi ve PMSG dozlarının birbirlerine göre $\chi^{2}$-uzaklıklarına bakılarak).

9. Ayrıca, satır değişkeninin (PMSG dozlarının) her bir seviyesi ile sütun değişkeninin (doğum tipi) her bir seviyesinin Şekil 1'deki bulundukları bölgeler $(++,++,-+,-)$ göz önüne alınarak da doz ve doğum tiplerine göre, ölüm frekansları arasındaki ilişkiler incelenebilir. Mesela, 400 IU dozu ile üçüz doğum tipi Şekil 1'de (++) yani 1. bölgede yer aldıklarından bunlar arasında pozitif yönde bir ilişskinin olduğu söylenebilir.

Bütün bu değerlendirmelerde, sadece sütun değişkeninin belirli bir seviyesi göz önüne alınıp satır değişkeninin çeşitli seviyeleri birbirleriyle karşılaştırılmaktadır.

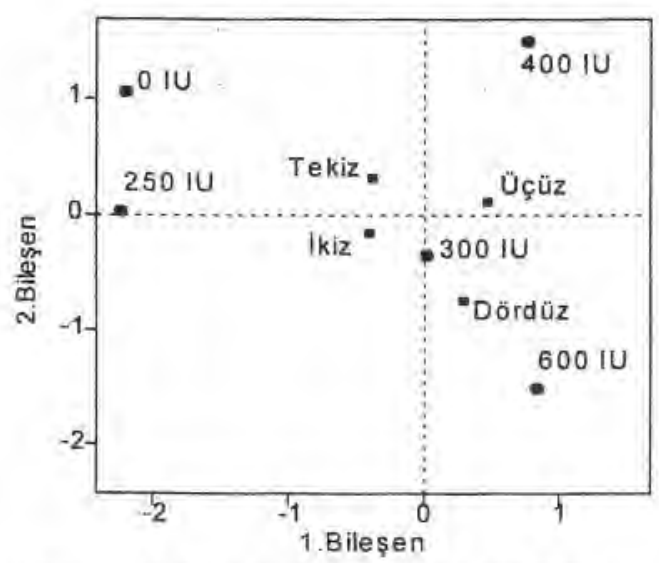

Şekil 1. Sütunlara göre uyum analizi sonuçlanı

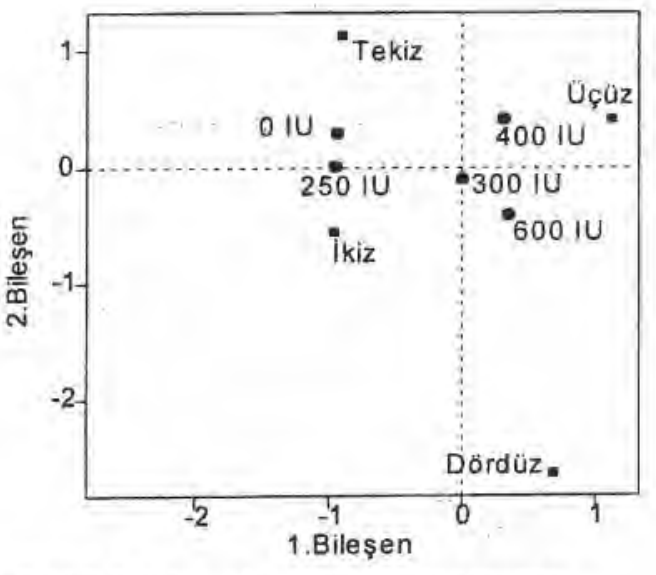

Şekil 2. Satırlara göre uyum analizi sonuçları

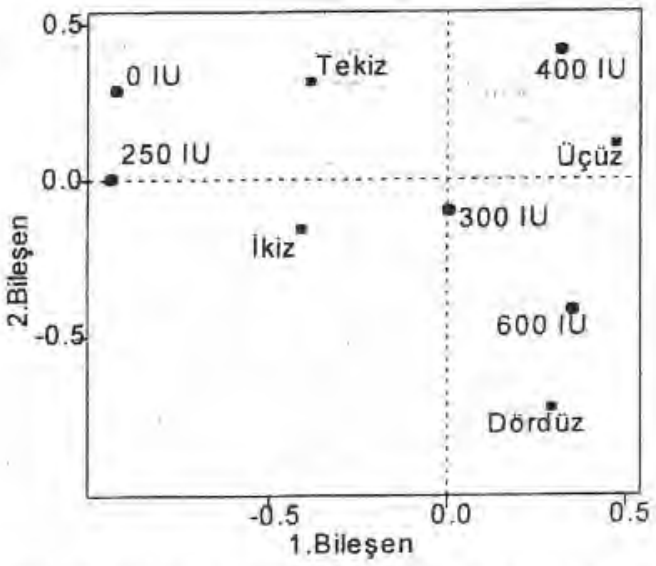

Şekil 3. Satır ve sütunlara göre uyum analizi sonuçları

Satır değişkeni (Şekil 2) esas alınarak bir değerlendirme yapılırsa;

1. 400 IU dozunun en çok üçüzlerde ölüm frekanslarını etkilediği,

2. 300 IU dozunun üçüzler üzerinde 400 IU dozundan daha az bir ölüme sebep olduğu,

3. 300 IU dozunun ikizlerde de üçüzlerdekine benzer bir etkiye sahip olduğunu.

4. Tekizlerin en fazla 0 IU dozunda ölüm frekanslarının fazla olduğunu, $250 \mathrm{IU}, 300 \mathrm{IU}$ ve $400 \mathrm{IU}$ dozlarının ise, yaklaşık olarak aynı etkiye sahip olduklarını,

5. $600 \mathrm{IU}$ dozunun kendisine en yakın olan ikiz ve üçüzlerde yaklaşık olarak aynı etkiye sahip olduğu,

6. Dördüzlerin ölüm frekansları üzerine ise, hemen hiçbir dozun etkili olmadığını söylemekle birlikte, kendisine en yakın olan 600 IU dozu ile ilişkili olduğu söylenebilir. 
Bu yorumlarda da sadece satır değişkeninin belirli bir seviyesi göz önüne alınarak sütun değişkeninin çeșitli seviyeleri birbirleriyle karșılaștırılırken satır değișkeninin diğer halleri göz ardı edilmektedir.

Satır ve sütun deg̃işkenleri birlikte (Şekil 3) ele alındığında;

1. 400 IU dozunun üçüzlerde ölüm frekansını etkilediğini ve $(++)$ bölgesinde bulunmalarından dolayı pozitif yönde ilișkili oldukları söylenebilir.

2. 600 IU dozunun daha ziyade dördüzlerde ölüm frekansı üzerinde etkili olduğu ve (+-) bölgesinde bulunmaları sebebiyle dozun artması durumunda dördüzlerde ölüm frekanslarında bir azalmanın olabileceğini, benzer bir etkiye daha az olmakla birlikte 300 IU dozunun da sebep olduğu iler sürülebilir.

3. Ikizlerde ölüm frekansları üzerine hemen hiçbir dozun etkili olmadığı söylenebilir.

4. Tekizlerde ölüm frekanslarının en çok 0 IU dozundan etkilendiği söylenebilir.

\section{Sonuç}

Sonuç olarak, yukarıda yapılan üç farkı yorumlamadan en sağlıklı bilgiyi veren ve araștırıcının amaçlarına en uygun olanı, satır ve sütun değiş̧enlerinin karşılıklı etkileşimlerinin göz önüne alındığı en son yorumlamalardır. Bu durum, Uyum Analizi tekniğinin alternatiflerine göre üstünlüklerini ortaya koymaktadır. Çünkü $\chi^{2}$-testinde, Fisher'in Kesin Olasılık Hesaplanmasında ve oranlara ait Z-testinde bu yorumlamalar yapılamamaktadır.

Araştırıcı isterse, sadece satır değişkenini göz önüne alarak (Şekil 1), sütun değişkeninin seviyelerini veya sadece sütun değişkenini göz önüne alarak (Şekil 2) satır değişkeninin seviyelerini karşılaştırabilir. Fakat bunun istatistik açıdan her hangi bir sakıncası olmamakla birlikte, bilgi kaybına sebep olacağı da göz ardı edilmemelidir.

\section{Kaynaklar}

Andersen, E.B. 1990. The Statistical Analysis of Categorical Data. Springer-Verlag, New York. USA.

Devilles, J. and W.Karcher, 1991. Applied Multivariate Analysis Sar and Environmental Studies. Kluwer Acad.Pub., Dortrecht, The Netherlands.

Düzgüneş, O., T.Kesici, F.Gürbuzz,1993. Istatistik Metodları Ank.Öniv.Zir.Fak.Yayınları: 1291. Ders Kitabı: 369 II.Baski.

Greenacre, M.J. 1984. Theory and Applications of Correspondence Analysis. London Academic Press. UK.

Meulman, J.J. 1998. Optimal Scaling Methods for Graphical Multivariate Data Analysis. XIII Symposium on Computational Statistics, Bristol.

Nishisato, S. 1980 . Analysis of Categorical Data: Dual Scaling and its Applications. Toronto, Univ. Of Toronto Press. Canada.

Oztürk, A.K. ve G.Dellal, 1999. Border Leicester $\times$ Booroola (ff) $\times$ Merinos Melezi Koyunlarda Anestrus. Dönemi Esnasinda Farklı Dozlarda PMSG Uygulamasının Döl Verimi Üzerine Etkileri. A.Ü.Z.F. Tarım Bilimleri Dergisi, 5(3), 35-39.

Snedecor, G.W. and W.G. Cochran, 1980. Statistical Methods. Seventh Ed. The lowa State University Press. Ames, lowa, U.S.A. 507 s.

Sokal, R.R. and F.J.Rohlf, 1995. Biometry. The Principles and Practice of Statistics in Biological Research. Third Ed. W.H. Freeman and Co., New York. $887 \mathrm{~s}$.

Winer, B.J. 1971. Statistical Principles in Experimental Design. Second Ed. McGraw-Hill Book Co., New York. 907 s. 